\title{
Evolución de la Condición Poblacional del Camarón Cryphiops caementarius en el Río Cañete (2000-2015)
}

\author{
Evolution of the Population Status of Prawn Cryphiops caementarius \\ on CAÑete River (2000-2015) \\ José Wasiw G. ${ }^{1,2}$, Víctor Yépez P. ${ }^{1,3}$
}

\section{Resumen}

En base a prospecciones efectuadas en el río Cañete, Perú, en el periodo 2000-2015, se reporta información referente a aspectos biológicos pesqueros y poblacionales del camarón de río Cryphiops caementarius. Asimismo, se determinaron los parámetros físicoquímicos de calidad del agua para establecer su relación con la distribución del recurso a lo largo de la cuenca prospectada. Los resultados indican una fracción mínima de ejemplares con tallas superiores a los $120 \mathrm{~mm}(<5 \%)$. Según el análisis del parámetro «b» de la relación longitud-peso, la población evaluada estaría compuesta por ejemplares con un peso mayor respecto a su talla, mayor proporción de ejemplares machos, así como mayor densidad y biomasa media en los estratos altitudinales inferiores. La densidad y biomasa media del recurso calculada para el río Cañete tiende a recuperarse, después de la situación crítica alcanzada en 2012. Se tomó conocimiento oral del incremento de la presión de pesca, pesca ilegal y alteraciones antrópicas en la cuenca del río evaluado.

Palabras clave: camarón de río, río Cañete, pesca ilegal, densidad y biomasa, contaminación antrópica

\section{AbSTraCT}

Based on surveys in the Cañete river (Peru) in the period 2000-2015, information concerning fisheries and biological aspects of the population of fresh water prawn Cryphiops caementarius is reported. Also, physicochemical parameters of water quality were determined to establish the relationship between these and resource distribution throughout the watershed prospected. The main results indicate a minimum fraction of

${ }^{1}$ Área Funcional de Investigaciones de Recursos en Aguas Continentales (AFIRAC), Instituto del Mar del Perú, Callao, Lima, Perú

${ }^{2}$ E-mail:jwasiw@imarpe.gob.pe

${ }^{3}$ E-mail:vyepez@imarpe.gob.pe

Recibido: 30 de junio de 2016

Aceptado para publicación: 17 de octubre de 2016 
individuals with above $120 \mathrm{~mm}$ size $(<5 \%)$. According to the analysis of the «b» parameter of the length-weight relationship, the evaluated population will be composed of individuals with a higher weight relative to their size, higher proportion of male specimens, and higher density and mean biomass in the lower altitudinal strata. The density and average biomass resource calculated for the Cañete river tends to recover after the critical situation reached in 2012. Oral knowledge of increased fishing pressure, illegal fishing and anthropogenic alterations in river basins evaluated was noted.

Key words: fresh water prawn, Cañete river, illegal fishing, density and biomass, anthropogenic pollution

\section{INTRODUCCIÓN}

El «camarón de río» Cryphiops caementarius es la especie de palemónido que constituye el principal recurso pesquero de los ríos de la vertiente occidental de los Andes peruanos. Es un crustáceo de agua dulce, que se distribuye en los ríos de la costa del Perú y Chile, entre los $6^{\circ} 30^{\prime}$ y $33^{\circ}$ de latitud sur (Amaya y Guerra 1976; Bahamonde y Vila, 1971). Se estima que en la costa peruana el $80 \%$ del recurso está disponible en los ríos de Arequipa, en los cuales su explotación es de relativa importancia, habiéndose verificado un aumento significativo del esfuerzo pesquero desde la década de los 90 (Yépez, 2009).

En el Perú, el término «camarón de río» involucra a los géneros Cryphiops, Macrobrachium, Palaemon y Atya. Sin embargo, la captura comercial se sustenta en la especie $C$. caementarius, la cual tiene su área de máxima concentración en los ríos de la costa central y sur del país.

Las especies de camarón existentes en los ríos de la costa peruana, según Amaya y Guerra (1976), son:

- Cryphiops caementarius

- Macrobrachium americanum

- Macrobrachium gallus

- Macrobrachium inca

- Macrobrachium tenellum

- Macrobrachium diguetti
- Macrobrachium hancocki

- Macrobrachium transandicum

- Macrobrachium panamense

- Palaemon hancocki

- Atya rivalis (= Atya margaritacea)

El recurso está sometido a una intensa explotación, a lo cual se le suman las alteraciones del hábitat por procesos naturales de sequía y antrópicos relacionados con el uso del agua; asimismo, por las actividades agrícolas y mineras. Además, se tienen evidencias que la abundancia del camarón ha mermado notoriamente por la explotación irracional (uso de métodos ilícitos).

Estudios realizados en Chile (Meruane et al., 2006) muestran que la crianza (engorde) de $C$. caementarius a escala comercial podría contribuir, en teoría, a la producción sostenible y a bajar la presión sobre sus stocks, ya que se evitaría la extracción clandestina del recurso en los periodos de veda, logrando la preservación y el incremento de las poblaciones naturales. En el Perú, son escasas las experiencias relacionadas al engorde de la especie, y en todo caso corresponden a un nivel de experimentación.

La distribución de la especie está limitada a los ríos costeros, en promedio hasta los 1400 msnm (Báez, 1985); no obstante, Hartmann (1958) la reportó hasta los 2000 msnm, pero condicionado por el grado de desnivel del lecho del río. Esta especie no habita cursos de agua con temperatura me- 


\title{
FLUJO MIGRATORIO DEL CAMARÓN
}

\author{
- En el Rio propiamente dicho se encuentran los adultos, juveniles y eventualmente las \\ larvas zoea I. \\ - En el Estuario se encuentran adultos, juveniles, pos larvas y larvas zocas I y II. \\ - En el Mar se encontrarian los estadios intermedios de zoea II a pos larvas, \\ desconociéndose el número exacto de zoeas en el ciclo evolutivo.
}

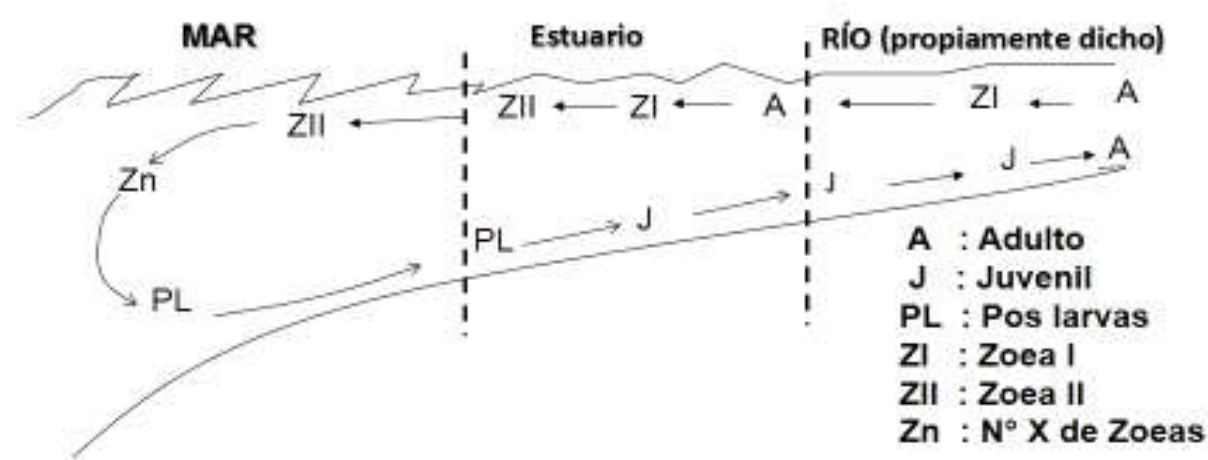

Figura l. Ciclo vital del camarón de río Cryphiops caementarius (larvas-poslarvas-juveniladulto). Fuente: Viacava et al. (1978)

nor de $10^{\circ} \mathrm{C}$ (Castro, 1966), y tiene la cualidad de refugiarse en el interior de cuevas que construye con limo, entre las piedras y huecos, dejando sobresalir las antenas durante el día.

La máxima actividad reproductiva del recurso ocurre entre los meses de diciembre y marzo, coincidente con la estación de avenidas («aguas turbias»), durante la cual se veda su captura. Las áreas de cría se localizan principalmente en la parte baja de los cauces (próximas a la desembocadura). Las variaciones temporales en su reproducción tienen relación con cambios en la temperatura, caudal y turbidez del agua (Viacava et al., 1978).

Los ejemplares adultos permanecen en los estratos altitudinales superiores durante gran parte del año. Machos maduros e inmaduros y hembras inmaduras presentan una mayor abundancia en zonas medias y al- tas de los ríos, mientras que las hembras maduras y aquellas que portan huevos se distribuyen mayormente en las zonas bajas, concentrándose en los últimos 20 a 30 kilómetros y en áreas cercanas a la desembocadura (estuario), siendo allí donde se produce la eclosión de los huevos (Bahamonde y Vila 1971; Norambuena, 1977; Rivera et al., 1983; Meruane et al., 2006). Asimismo, los ejemplares adultos se encuentran en zonas de mayor profundidad y los juveniles en zonas someras (mayoritariamente en orillas o bordes del río) (Castro, 1966).

La primera parte de la vida larvaria transcurre en ambientes estuarino-marinos. En aquellos ríos cuyas desembocaduras presentan acentuadas zonas de mezcla de agua y/o una directa conexión al mar, existe gran disponibilidad de ejemplares en estadios tempranos de desarrollo (Rivera et al., 1983). A medida que progresa el desarrollo, las poslarvas comienzan a remontar el curso de 


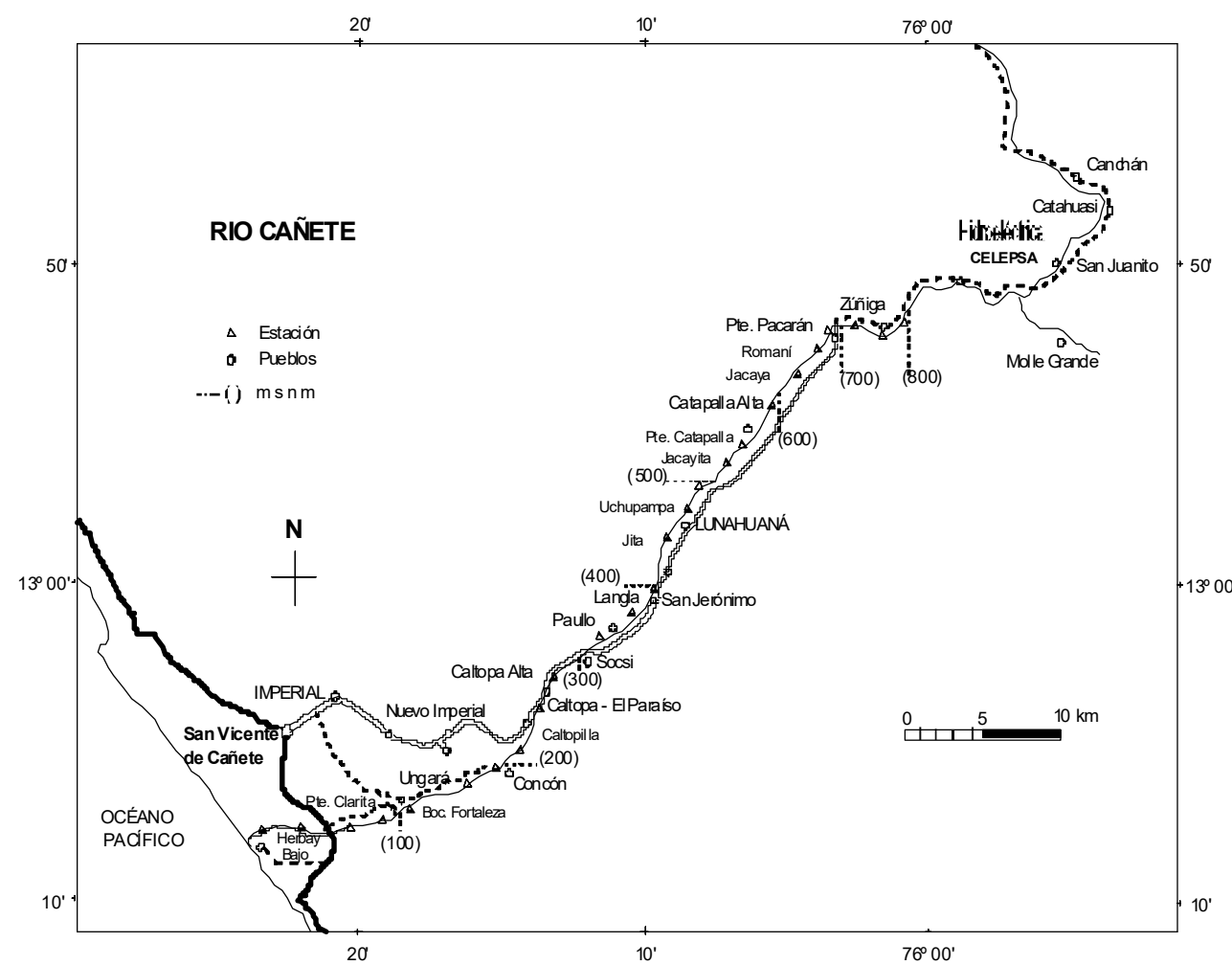

Figura 2. Estaciones de muestreo para evaluación de camarón en el río Cañete (agosto de 2015)

los ríos, para incorporarse como reclutas a la población distribuida río arriba (Viacava et al., 1978) (Figura 1). El proceso de distribución de larvas de C. caementarius en las zonas de mezcla de agua dulce y de mar ha sido observado en las desembocaduras de los ríos Majes-Camaná y Pativilca (Hartmann 1958, Viacava et al., 1978).

Desde 1996, el Instituto del Mar del Perú desarrolla un plan de monitoreo poblacional del recurso, a fin de aportar la base consistente para el manejo de su pesquería. El mismo comprende la realización de prospecciones anuales en los ríos de la costa centro-sur, dirigidas principalmente a determinar índices de concentración y estimar niveles de abundancia de los stocks comerciales y precomerciales en los ríos donde existe extracción intensa del recurso. El presente informe contiene los resultados reportados durante los monitoreos poblacionales de camarón en el río Cañete (Lima), ejecutados en el periodo 2000-2015 (mayoritariamente entre julio y setiembre), con especial referencia a los stocks de adultos.

\section{Materiales y Métodos}

\section{Esquema de Muestreo}

Según el esquema de estratificación establecido en las prospecciones iniciales del programa de monitoreo, los cauces de los ríos son divididos en estratos de $100 \mathrm{~m}$ de altitud, donde se establecen las estaciones para pesca exploratoria. Previamente, se realiza su ubicación por cartografía y luego se comprueba in situ las condiciones de acceso.

El área de sección mojada o espejo de agua de cada estrato, elemento base para las estimaciones poblacionales, se determina considerando la longitud del curso (definido por cartografía) y en el terreno se mide el ancho 
Cuadro 1. Escalas de madurez gonadal del camarón de río Cryphiops caementarius, según sexo

\begin{tabular}{lll}
\hline Escala & Hembras & Machos \\
\hline I & Inmadurez & Inmadurez (Maduración incipiente) \\
II & Maduración incipiente & Madurez intermedia \\
III & Maduración intermedia & Madurez avanzada (desove) \\
IV & Maduración avanzada (desove) & Posdesove \\
V & Posdesove & \\
\hline
\end{tabular}

promedio del lecho; ajustándose ambas magnitudes por coeficientes referidos a factores de sinuosidad y ramal o brazo. Si bien, en general, la sinuosidad del río Cañete es baja y corresponde al tipo de cauce «canal recto» (Guevara, 2003), es necesario considerarlo en ciertos tramos.

Los trabajos de campo (análisis de parámetros físicoquímicos del agua y faenas de pesca) se ejecutaron en el cauce comprendido entre 0 y $800 \mathrm{msnm}$ (24 estaciones). No obstante, cabe señalar que los monitoreos de estimación poblacional que se ejecutaron hasta el 2009, comprendieron el rango altitudinal entre los 0 y $1000 \mathrm{msnm}$ (32 estaciones de muestreo) y, a partir del 2010, debido a la construcción de la Central Eléctrica El Platanal S.A. (CELEPSA), las evaluaciones se realizan entre 0 y $800 \mathrm{msnm}$. En la Figura 2 se muestran los detalles relacionados a la estratificación del cauce y la ubicación de las estaciones de evaluación.

\section{Características Abióticas del Medio Hídrico}

El registro de los parámetros limnológicos de calidad del agua en el cauce del río Cañete se realizó considerando que el análisis de la relación recurso-ambiente es trascendente para el conocimiento del estado poblacional de los recursos pesqueros, $\mathrm{y}$ que cada especie es altamente dependiente del entorno que la rodea.
Los parámetros fisicoquímicos de calidad de agua corresponden a temperatura del agua y el ambiente (termómetro protegido, precisión $\left.0.1^{\circ} \mathrm{C}\right), \mathrm{pH}$ (pHmetro digital), oxígeno disuelto, concentración y porcentaje de saturación (Oxímetro YSI), así como $\mathrm{CO}_{2}$ libre, dureza, alcalinidad total ( $\operatorname{como~} \mathrm{CaCO}_{3}$ ) y la fenolftaleína, cloruros disueltos y $\mathrm{ClNa}$, medidos mediante kits comerciales específicos (Hach, EEUU). Las muestras de agua fueron obtenidas a nivel superficial en la zona de orilla, realizándose los análisis in situ.

\section{Faenas de Pesca Experimental}

Las capturas del recurso en las estaciones de evaluación se realizaron mediante el método del «buceo a pulmón». La operación de pesca consideró un «barrido» contra corriente, efectuado por un equipo de ocho extractores experimentados, quienes recorrieron transectos de $40 \mathrm{~m}$ de largo en dos entradas, en un periodo aproximado de 20 minutos (dependiendo del tipo de fondo y caudal del río).

Se contaron y pesaron los especímenes capturados por transecto por cada pescador. Asimismo, se registró el número de ejemplares que no pudieron ser atrapados («escapes») según información de cada extractor, a fin de estimar factores de eficiencia en la operación de pesca y los respectivos índices de abundancia. 


\section{Muestreo Biológico y Biométrico}

Se separó al azar una muestra de 60 especímenes de las capturas obtenidas por estación para los análisis respectivos, y en los casos de capturas de menor número se analizaron todos los individuos. La medición y peso de ejemplares se realizó mediante el uso de vernier mecánico y balanza electrónica portátil con $0.1 \mathrm{~g}$ de precisión. Los individuos fueron medidos al milímetro y separados en clases o intervalos de $5 \mathrm{~mm}$ a la unidad inferior.

Los datos biométricos y biológicos registrados corresponden a longitud total $(\mathrm{mm})$, longitud del cefalotórax $(\mathrm{mm})$, peso total $(\mathrm{g})$, peso abdominal (g), sexo y madurez gonadal. Se anotaron observaciones con respecto a la falta de apéndices, estadio de madurez gonadal, estado reproductivo (ovígera y no ovígera), estado de la muestra, etc. La información obtenida se empleó para determinar los principales «parámetros biológicos pesqueros» del recurso, así como de la condición reproductiva.

Para la determinación de la condición reproductiva se emplearon los porcentajes de estadios de madurez, basados en la escala de madurez para hembras y machos (Viacava et al., 1978). Se han descrito cinco estadios para el caso de las hembras y cuatro para los machos (Cuadro 1). Se entiende que los porcentajes de los ejemplares con estadios de madurez gonadal se van incrementando a medida que se aproximan al periodo de máxima actividad reproductiva.

\section{Aspectos Poblacionales}

La biomasa se estimó mediante una modificación del método por «área barrida», que consiste en calcular la densidad de la especie objetivo, relacionando las capturas con el área o sector de barrido efectivo, y extrapolándola a la totalidad del área de cada estrato. Para el efecto, se sigue el procedimiento descrito por Espino y Wosnitza-Mendo (1984). Con base en esto, el número y el peso de ejemplares capturados por extractor (considerando los escapes) en cada sección se emplearon para estimar densidades, concentración y población en número y biomasa por estratos del río que, a su vez, sirvieron para determinar las variaciones poblacionales por año.

La metodología empleada por IMARPE para los estimados poblacionales del camarón de río $C$. caementarius es como sigue:

\section{Densidades (D)}

Para estimar la densidad (ind $/ \mathrm{m}^{2}$ ) del transecto 1 (primer extractor) de la estación 1 se usó la fórmula:

$$
\mathrm{Dt} 1=(\mathrm{Ce} 1+\mathrm{Ee} 1) / \mathrm{a}
$$

donde:

$\mathrm{Cel}=$ Captura total obtenida por el extractor 1 en el transecto ( $\mathrm{N} .{ }^{\circ}$ de individuos)

$E e 1=$ Número total de individuos que se escapan ( $\mathrm{N} .{ }^{\circ}$ de individuos)

$\mathrm{a}=$ Área barrida por el extractor en el transecto $\left(\mathrm{m}^{2}\right)$

Seguidamente se estima la densidad promedio $\left(D_{\text {Estaciónl }}\right)$ para la estación 1 (considerando los ocho extractores). Luego se estima la densidad media por estrato altitudinal $\left(D_{\text {Estrato }}\right.$ ) (considerando el número de estaciones en el estrato). La Densidad Total $\left(D_{\text {Total }}\right)$ del río (ind $\left./ \mathrm{m}^{2}\right)$ se estima al promediar las densidades de todos los estratos.

\section{Abundancia (Ab)}

La abundancia $\left(A b_{\text {Estratol }}\right)$ en número de individuos se estima multiplicando la $D_{\text {Estrato } 1}$ por el área del estrato $A_{\text {Estratol }}\left(\mathrm{en} \mathrm{m}^{2}\right)$. Es decir: $A b_{\text {Estratol }}=D_{\text {Estratol }} \times A_{\text {Estratol }}$, y donde el área del estrato $A_{\text {Estratol }}\left(\mathrm{en} \mathrm{m}^{2}\right.$ ) se estima con la fórmula: $A_{\text {Estratol }}=L_{\text {Estratol }}$ x $a_{\text {Estratol }} \mathrm{x}$ $F b_{\text {Estratol }} \times F m_{\text {Estratol }}$ donde:

$L_{\text {Estratol }}=$ Longitud (en m) del estrato obtenido por cartografía (mapa)

$a_{\text {Estratol }}=$ Ancho promedio (en $\mathrm{m}$ ) del río en el estrato 
Cuadro 2. Parámetros físicoquímicos promedio de calidad de agua según estratos de altitud del río Cañete (2000-2015)

\begin{tabular}{|c|c|c|c|c|c|c|c|c|c|c|c|c|}
\hline \multirow{2}{*}{$\begin{array}{l}\text { Estrato } \\
\text { (msnm) }\end{array}$} & \multicolumn{2}{|c|}{$\begin{array}{c}\text { Temperatura } \\
\left({ }^{\circ} \mathrm{C}\right)\end{array}$} & \multirow[t]{2}{*}{$\mathrm{pH}$} & \multicolumn{2}{|c|}{ Oxígeno } & \multirow{2}{*}{$\begin{array}{c}\mathrm{CO}_{2} \\
(\mathrm{mg} / \mathrm{L}) \\
\end{array}$} & \multirow{2}{*}{$\begin{array}{l}\text { Dureza } \\
(\mathrm{mg} / \mathrm{L})\end{array}$} & \multirow{2}{*}{$\begin{array}{l}\text { Alcal. } \\
\text { total }\end{array}$} & \multirow{2}{*}{$\begin{array}{c}\text { Nitritos } \\
(\mathrm{mg} / \mathrm{L})\end{array}$} & \multirow{2}{*}{$\begin{array}{l}\text { Nitratos } \\
\text { (mg/L) }\end{array}$} & \multirow{2}{*}{$\begin{array}{c}\mathrm{Cl} \\
(\mathrm{mg} / \mathrm{L}) \\
\end{array}$} & \multirow{2}{*}{$\begin{array}{c}\mathrm{CINa} \\
(\mathrm{mg} / \mathrm{L})\end{array}$} \\
\hline & Agua & Amb & & $(\mathrm{mg} / \mathrm{L})$ & (\%sat) & & & & & & & \\
\hline $01-1000$ & 19.0 & 23.3 & 8.8 & 6.7 & 104.8 & 12.2 & 237.0 & 151.8 & 0.00 & 0.08 & 70.1 & 94.6 \\
\hline 801-900 & 20.0 & 22.9 & 8.6 & 6.9 & 101.7 & 10.9 & 227.0 & 159.2 & 0.00 & 0.06 & 66.1 & 88.8 \\
\hline $701-800$ & 19.0 & 22.3 & 8.7 & 7.5 & 96.8 & 12.6 & 250.8 & 157.9 & 0.37 & 0.28 & 75.7 & 114.9 \\
\hline $601-700$ & 19.9 & 22.2 & 8.7 & 7.5 & 97.9 & 12.7 & 245 & 1 & 0.67 & 20 & 82.2 & 125.3 \\
\hline 501-600 & 20.6 & 22.5 & 8.8 & 7.7 & 99.1 & 12.7 & 235.6 & 149.4 & 1.70 & 0.27 & 80.3 & 122.5 \\
\hline $401-500$ & 20.6 & 22.6 & 8.8 & 7.9 & 101.3 & 11.9 & 233.7 & 155.3 & 0.67 & 0.35 & 81.5 & 123.9 \\
\hline $301-400$ & 20.3 & 21.1 & 8.8 & 8.4 & 104.8 & 12.1 & 232.3 & 144.8 & 0.37 & 0.44 & 82.4 & 125.6 \\
\hline 201- & 20.7 & 20.2 & 8.8 & 8.4 & 106.0 & 12.7 & 230.9 & $14 \mathrm{~J}$ & 0.67 & 0.10 & 76.6 & 116.3 \\
\hline $101-200$ & 21.3 & 21.1 & 8.8 & 8.8 & 111.1 & 12.4 & 224.2 & 150.7 & 0.15 & 0.18 & 78.3 & 118.9 \\
\hline $0-100$ & 21.1 & 20.0 & 8.8 & 9.2 & 115.3 & 13.1 & 238.5 & 146.8 & 1.00 & 0.34 & 82.5 & 124.6 \\
\hline
\end{tabular}

$F b_{\text {Estratol }}=$ Factor brazo o ramal medio del río en el estrato

$\mathrm{Fm}_{\text {Estratol }}=$ Factor meandro o sinuosidad media del río en el estrato

La Abundancia total $\left(A b_{\text {Total }}\right)$ para el río se obtiene sumando las abundancias de todos los estratos evaluados.

\section{Biomasa media $\left(\mathrm{g} / \mathrm{m}^{2}\right)$}

La biomasa $\left(b t_{1}\right)$ para el transecto barrido por el primer extractor será:

donde:

$$
b t_{1}=\left(C e_{1}+E e_{1}\right) / a
$$

$C e_{1}=$ Captura total obtenida en peso por el extractor en el transecto (g)

$E e_{1}=$ Escape total de individuos en peso (g) $\mathrm{a}=$ Área barrida por el extractor en el transecto $\left(\mathrm{m}^{2}\right)$

Seguidamente, se estima la biomasa promedio $\left(b_{\text {Estación } 1}\right)$ para la estación 1 (considerando ocho extractores), y luego se estima la biomasa media del estrato altitudinal $\left(b_{\text {Estrato }}\right)$ (considerando las estaciones del estrato). Para ello se multiplica la $\left(b_{\text {Estación } 1}\right)$ por el área del estrato $A_{\text {Estrato } I}$. Finalmente, la Biomasa Media total $\left(b_{\text {Total }}\right)$ del río $\left(\mathrm{g} / \mathrm{m}^{2}\right)$ se estima al promediar las biomasas medias de todos los estratos.

Biomasa (B)

Para estimar la Biomasa absoluta $(\mathrm{kg})$ del estrato 1, se multiplica la biomasa por unidad de área en kilos $\left(\mathrm{kg} / \mathrm{m}^{2}\right)$ del estrato 1 , por el área del estrato $1\left(A_{\text {Estratol }}\right)$ anteriormente calculado $\left(B_{\text {Estratol }}=b_{\text {Estratol }} \mathrm{x}\right.$ $\left.A_{\text {Estratol }}\right)$. La Biomasa total $\left(B_{\text {Total }}\right)$ para el río se obtiene sumando las biomasas de todos los estratos evaluados

\section{Resultados y Discusión}

\section{Principales Parámetros Fisicoquímicos de Calidad del Agua}

Los resultados anuales de los principales parámetros fisicoquímicos de calidad del agua obtenidos en el cauce del río Cañete, evaluados hasta el 2015 (Cuadro 2), evidenciaron condiciones favorables para el desa- 
Cuadro 3. Rangos anuales de talla $(\mathrm{mm})$ del camarón Cryphiops caementarius en el río Cañete (2000-2015)

\begin{tabular}{cccccc}
\hline Año & Mínimo & Máximo & Rango & Moda & Juveniles (\%) \\
\hline 2000 & 28 & 130 & 102 & 55 & 66.1 \\
2001 & 25 & 130 & 105 & 65 & 62.8 \\
2002 & 25 & 149 & 124 & 65 & 48.7 \\
2004 & 23 & 133 & 110 & 70 & 51.4 \\
2005 & 25 & 128 & 103 & 52 & 51.9 \\
2006 & 21 & 127 & 106 & 62 & 47.7 \\
2007 & 28 & 127 & 99 & 57 & 48.6 \\
2008 & 24 & 132 & 108 & 57 & 56.9 \\
2009 & 25 & 144 & 119 & 57 & 52.2 \\
2010 & 27 & 126 & 99 & 66 & 54.4 \\
2011 & 28 & 127 & 99 & 52 & 47.0 \\
2012 & 24 & 133 & 109 & 60 & 52.0 \\
2013 & 21 & 125 & 104 & 50 & 74.0 \\
2014 & 21 & 128 & 107 & 62 & 47.9 \\
2015 & 24 & 115 & 91 & 54 & 65.9 \\
\hline Mínimo & 21 & 115 & 91 & 50 & 47.0 \\
Máximo & 28 & 149 & 124 & 70 & 74.0 \\
\hline
\end{tabular}

rrollo poblacional del recurso camarón de río C. caementarius.

Diversos autores reportan que los cursos de agua con condiciones aparentes para el desarrollo del camarón de río, son aquellos cuyos valores se encuentran dentro de los siguientes rangos: temperatura 15 a $27^{\circ} \mathrm{C}$, $\mathrm{pH} 6.5$ a 9.0, oxígeno disuelto $5 \mathrm{a} 10 \mathrm{mg} / \mathrm{L}$, alcalinidad total 100 a $200 \mathrm{mg} / \mathrm{L}$ y dureza total 150 a $400 \mathrm{mg} / 1$ de $\mathrm{CaCO}_{3}$ (Bahamonde y Vila, 1971; Chávez et al., 1973; Norambuena, 1977; Viacava et al., 1978; Meruane et al., 2006).

En general, se evidencian mayores valores de concentración de $\mathrm{CO}_{2}$ y alcalinidad en zonas ribereñas próximas a poblados y áreas de cultivos (especialmente en las esta- ciones de muestreo cercanas a la zona de estuario del río, donde existe una mayor carga orgánica). Asimismo, se observa que existe relación inversa entre la altitud y la concentración de oxígeno disuelto, siendo que el sector inferior de la cuenca presenta los mayores valores; lo cual podría deberse a la presencia de focos de alta productividad primaria (ocasionada por el mayor aporte de nutrientes). Esto último, si bien puede inferirse de la coloración de las aguas (verdosas), debiera ser motivo de un estudio de calidad del medio acuático que permita ampliar el conocimiento sobre la ecología de este cuerpo de agua.

Durante el periodo de estudio, se ha observado evidencia de envenenamiento de las aguas para captura del camarón, incremento 
de la turbidez producto de diferentes acciones antrópicas e ingreso de aguas procedentes de actividades agrícolas y domésticas sin tratamiento.

\section{Aspectos Biológicos de los Stocks Co- merciales}

Composición por tallas

El rango de la estructura de tallas de los ejemplares capturados a través de los años del estudio presentó valores mínimos de 21 a $28 \mathrm{~mm}$ y valores máximos de 125 a $149 \mathrm{~mm}$, con una moda de 50 a $70 \mathrm{~mm}$. Asimismo, la proporción de ejemplares con tallas inferiores a la talla mínima de captura del camarón de río $\left(\mathrm{TMC}=70 \mathrm{~mm}\right.$ ) (R.M. N. ${ }^{\circ}$ 209-2001$\mathrm{PE})$ varió entre 47 y $74 \%$ del total de las capturas, alcanzando el valor máximo de $74 \%$ en 2013 (Cuadro 3; Figura 3). Por otro lado, considerando los porcentajes acumulados de las longitudes totales durante el periodo evaluado y la talla mínima de captura del recurso, se estimó que cerca del $71 \%$ de los ejemplares capturados presentaron tallas inferiores a la TMC (Figura 4).

La fracción de ejemplares con tallas superiores a los $120 \mathrm{~mm}$ cada año es menor, y en 2013 fue prácticamente nula $(0.1 \%)$, año en el que registró la menor talla máxima. Asimismo, por referencias de los pescadores y lugareños es de conocimiento que sobre los 1000 msnm existían camarones con tallas superiores a los $150 \mathrm{~mm}$. Actualmente, no se puede dar mayores detalles al respecto, puesto que las evaluaciones de IMARPE no incluyen este sector del río, que ya ha sido aislado parcialmente por la represa de CELEPSA.

Por otra parte, en 2015 existió el predominio de ejemplares de 45-60 $\mathrm{mm}$ de longitud, lo que evidencia moderado decremento de la moda con relación a $2014(55-70 \mathrm{~mm})$, pero en términos generales corresponden a valores cercanos a los registrados en años previos. La situación poblacional poco favorable del recurso en el río Cañete sería con- secuencia de la alteración en el ciclo hídrico del cauce del río, posteriormente a la entrada en operación de la central eléctrica CELEPSA, y a factores de origen antrópico, como el incremento del esfuerzo pesquero (sobrepesca) con la extracción dirigida a ejemplares de mayores tallas; condicionado ello por la mayor accesibilidad a zonas de

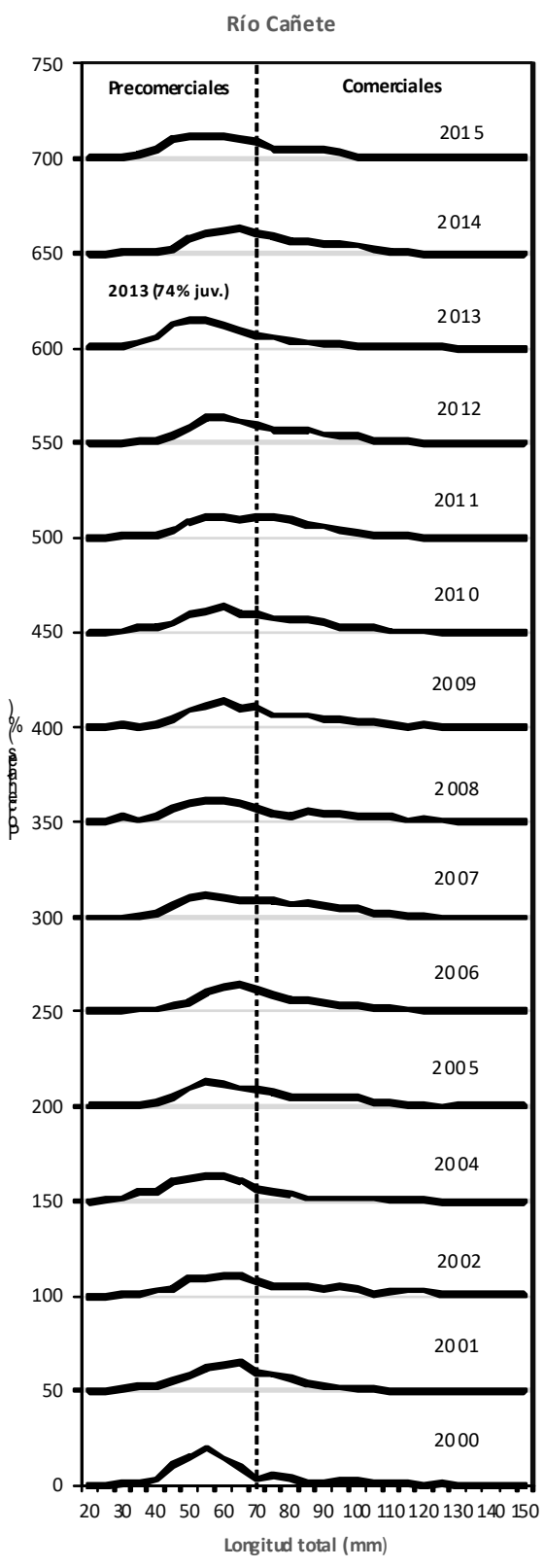

Figura 3. Variación anual de tallas del camarón Cryphiops caementarius en el río Cañete (2000-2015) 


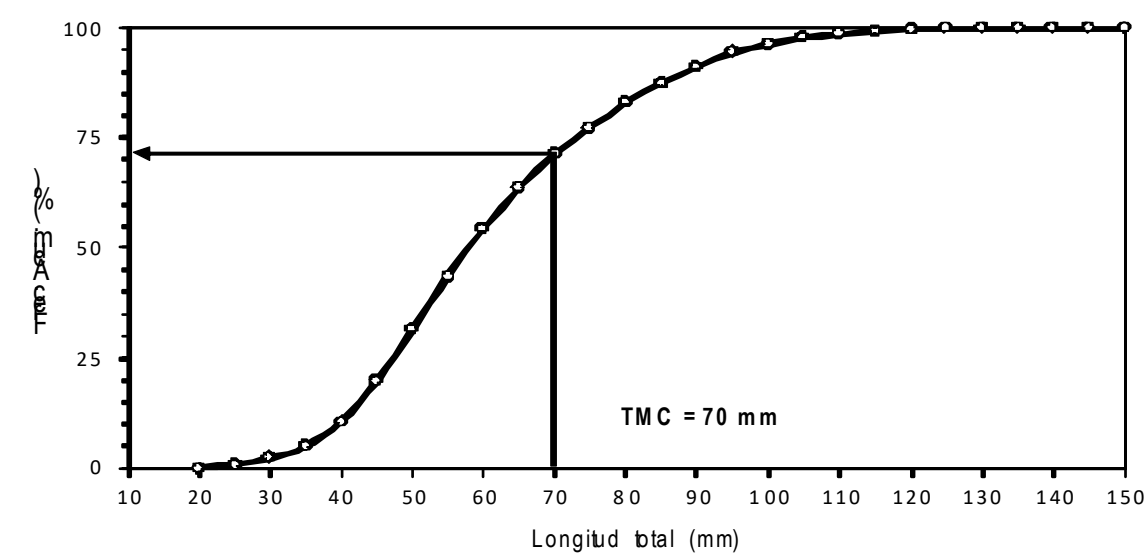

Figura 4. Frecuencia acumulada de longitudes de camarón Cryphiops caementarius en el río Cañete (2000-2015)

Cuadro 4. Variación anual de los parámetros de la relación longitud total (Lt) vs peso total $(\mathrm{Pt})$ y peso abdominal $(\mathrm{Pab})$ vs peso total $(\mathrm{Pt})$ del camarón Cryphiops caementarius en el río Cañete (2000-2015)

\begin{tabular}{cccccccccc}
\hline \multirow{2}{*}{ Años } & \multicolumn{3}{c}{ Lt vs Pt } & \multicolumn{3}{c}{ Pab vs Pt } & \multicolumn{3}{c}{ Pab vs Pt $(>7 \mathrm{~cm})$} \\
\cline { 2 - 10 } & $\mathrm{a}$ & $\mathrm{b}$ & $\mathrm{r}^{2}$ & $\mathrm{a}$ & $\mathrm{b}$ & $\mathrm{r}^{2}$ & $\mathrm{a}$ & $\mathrm{b}$ & $\mathrm{r}^{2}$ \\
\hline 2000 & 0.00001 & 3.2011 & 0.9779 & 0.7410 & 0.3621 & 0.9695 & 1.6531 & 0.3334 & 0.9436 \\
2001 & 0.00001 & 3.2806 & 0.9643 & 0.9232 & 0.3534 & 0.9479 & 2.3037 & 0.3059 & 0.9292 \\
2002 & 0.00002 & 3.2533 & 0.9750 & 0.9066 & 0.3559 & 0.9665 & 1.7063 & 0.3365 & 0.9418 \\
2004 & 0.00020 & 3.1329 & 0.9582 & 1.2100 & 0.2839 & 0.9319 & 2.8469 & 0.2435 & 0.9051 \\
2005 & 0.00001 & 3.2322 & 0.9822 & 0.7657 & 0.3648 & 0.9666 & 1.5241 & 0.3385 & 0.9287 \\
2006 & 0.00001 & 3.2866 & 0.9651 & 1.0032 & 0.3454 & 0.9558 & 1.8861 & 0.3148 & 0.9229 \\
2007 & 0.00001 & 3.2270 & 0.9841 & 0.6992 & 0.3759 & 0.9715 & 1.5520 & 0.3420 & 0.9405 \\
2008 & 0.00001 & 3.2457 & 0.9868 & 0.7018 & 0.3697 & 0.9634 & 1.9209 & 0.3330 & 0.9118 \\
2009 & 0.00001 & 3.3448 & 0.9824 & 0,7734 & 0.3514 & 0.9636 & 1.7054 & 0.3221 & 0.9325 \\
2010 & 0.00001 & 3.3334 & 0.9754 & 0.6540 & 0.3628 & 0.9679 & 1.5152 & 0.3308 & 0.9352 \\
2011 & 0.00001 & 3.3002 & 0.9810 & 0.6578 & 0.3632 & 0.9719 & 1.2126 & 0.3415 & 0.9489 \\
2012 & 0.00001 & 3.2486 & 0.9673 & 0.8775 & 0.3470 & 0.9746 & 1.5599 & 0.3262 & 0.9599 \\
2013 & 0.00001 & 3.2570 & 0.9791 & 0.6750 & 0.3608 & 0.9753 & 1.3817 & 0.3349 & 0.9551 \\
2014 & 0.00001 & 3.2533 & 0.9754 & 0.8000 & 0.3664 & 0.9704 & 1.3819 & 0.3386 & 0.9403 \\
2015 & 0.00002 & 3.1740 & 0.9678 & 0.6004 & 0.3696 & 0.9667 & 1.5425 & 0.3329 & 0.9159 \\
\hline
\end{tabular}

pesca, así como al aumento de la contaminación directa e indirecta del agua y de la pesca ilegal. Al respecto, la mayor probabilidad de ocurrencia de capturas ilícitas con relación a la TMC se aprecia entre los 0 y 200 msnm (incluyendo la zona de estuario). 
Cuadro 5. Proporción sexual anual (M:H) por estratos y total del camarón Cryphiops caementarius en el río Cañete (2000-2015)

\begin{tabular}{|c|c|c|c|c|c|c|c|c|c|c|c|c|c|c|c|}
\hline Estratos & 2000 & 2001 & 2002 & 2004 & 2005 & 2006 & 2007 & 2008 & 2009 & 2010 & 2011 & 2012 & 2013 & 2014 & 2015 \\
\hline $00-901$ & & & & & & & 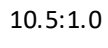 & & $3.4: 1$ & & & & & & \\
\hline $900-801$ & & 0.1. & 7. & $0.8:$ & $1.5:$ & $1.2: 1.0$ & $8: 1.0$ & $26.0: 1.0$ & 2.0:1.0 & & & & & & \\
\hline $800-701$ & $1.0: 1.0$ & $1.2: 1$ & $5.1: 1.0$ & $0.9: 1.0$ & $1.7: 1.0$ & 2.0:1.0 & $3.7: 1.0$ & $11.8: 1.0$ & 2.6:1.0 & 2.0: & 6.9:1.0 & $5.5: 1.0$ & $1.0:$ & $0.9: 1.0$ & $2.0: 1.0$ \\
\hline $700-601$ & & 1.1: & $\epsilon$ & 1.0 & 2.4 & 2.6 & 19 & 4 & $1.6: 1.0$ & 5.4 & $3.4: 1.0$ & $2.8: 1.0$ & 1.6: & 2.7 & 2.5:1.0 \\
\hline 600-501 & $5: 1.0$ & $0.9: 1$ & $2.0: 1.0$ & $1.8: 1.0$ & $2.5: 1.0$ & $2.4: 1.0$ & $3.7: 1.0$ & .0 & $4.6: 1.0$ & 5. & 6.8 & 3.3 & 2. & 50 & $3: 1.0$ \\
\hline 500-401 & $1.0: 1.0$ & $0.6: 1$ & $1.8: 1.0$ & & $2.3: 1.0$ & 2.6:1.0 & $5.9: 1.0$ & 3.0:1.0 & $4.3: 1.0$ & 2.9: & $8.4: 1.0$ & $3.8: 1.0$ & 1.3: & $6.3: 1.0$ & $4.2: 1.0$ \\
\hline 400-301 & $1.3: 1.0$ & 0.7 & 0.9 & 0.6 & 2. & 2. & $: 1.0$ & 1. & $1.7: 1.0$ & 1. & 3.2 & 2 & 1 & 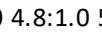 & $: 1.0$ \\
\hline $300-201$ & $1.4: 1.0$ & $0.6: 1$ & $2.2: 1.0$ & $1.0: 1.0$ & 2.8 & $2.0: 1.0$ & 1.0 & $1.5: 1.0$ & $1.3: 1.0$ & 2. & 2.1 & 2.4 & 1.8 & 4. & $3.0: 1.0$ \\
\hline 200-101 & $1.8: 1.0$ & $0.8:$ & 1.9 & $0.8: 1.0$ & 2.9 & $1.7: 1.0$ & $4.4: 1.0$ & $1.7: 1.0$ & $1.9: 1.0$ & & ט. & 2.2 & . & 0. & $4.2: 1.0$ \\
\hline $100-0$ & 7:1.0 & $1.0: 1$ & $1.1: 1.0$ & $0.4: 1.0$ & 2.0 & $0.8: 1.0$ & $1.9: 1.0$ & $0.8: 1.0$ & $2.8: 1.0$ & $1.2: 1.0$ & 0.9:1.0 & $0.7: 1.0$ & $0.8: 1.0$ & $1.6: 1.0$ & 2.2:1.0 \\
\hline & & & & & & & & & & & & & & & \\
\hline
\end{tabular}
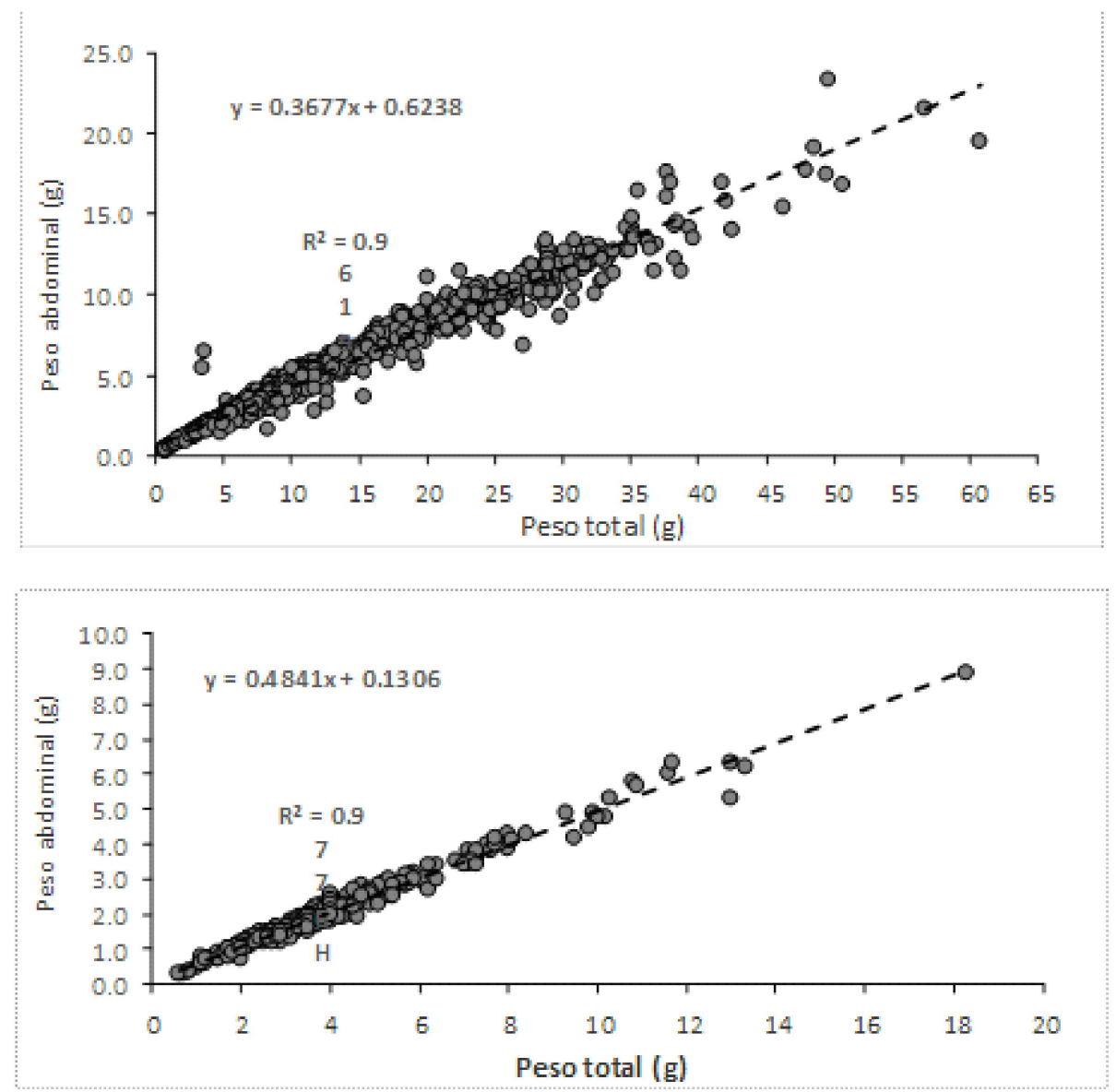

Figura 5. Relación Peso total vs Peso abdominal del camarón Cryphiops caementarius, según sexo, en el río Cañete (2000-2015) 


\section{Relación Longitud total-Peso total y Peso total-Peso abdominal}

Los resultados de los análisis de la relación longitud - peso por año evidenciaron que el camarón corresponde a poblaciones compuestas por ejemplares que presentan mayor peso con respecto al correspondiente a su talla. Las variaciones anuales del coeficiente de crecimiento «b» no fueron significativas (prueba del Chi cuadrado). Los valores variaron entre 3.13 (2004) y 3.35 (2009), que corresponden a un crecimiento de tipo isométrico, según Carlander (1969), en la que el valor del exponente «b» debe normalmente situarse entre 2.5 y 3.5 (Cuadro 4).

La relación talla - peso analizada determinó mayor peso para los ejemplares machos que en las hembras. Esta diferencia en el peso estaría relacionada al desarrollo desproporcionado de una de las dos quelas de los ejemplares machos, en especial en el caso de los ejemplares «chirire» en el sector bajo de la cuenca y «chumbo» en el sector superior de la cuenca (Viacava et al., 1978). En las hembras, el mayor incremento en peso estaría relacionado a la presencia de ejemplares en condición de ovígeras que portan los huevos entre los pleópodos. Por otro lado, los valores reportados para $\mathrm{r}^{2}(\min =0.9582$ y máx $=$ 0.9868 ) demuestran la fuerte interrelación que existe entre las variables longitud total y peso total.

La relación peso total - peso abdominal (de tipo lineal) permite conocer el peso total comercial neto (compuesto tan solo por colas), verificándose que se habría registrado un buen rendimiento en los últimos años (Cuadro 4). Esta condición reportada sería el reflejo de una población compuesta mayoritariamente por ejemplares machos, los que alcanzan mayores pesos que las hembras, y que concuerda plenamente con los resultados de la proporción sexual (M:H) por estratos y total (Cuadro 5; Figura 5).
Proporción de sexos

La proporción entre machos y hembras (sex ratio) en las poblaciones naturales suele ser cercana a $1: 1$, con igual número de descendientes de uno y otro sexo. El patrón natural de distribución altitudinal del camarón de río corresponde a un predominio de los ejemplares hembra en los estratos altitudinales inferiores y de machos en los superiores (Viacava et al., 1978). Se reporta el predominio de los ejemplares machos en los diferentes estratos altitudinales del río Cañete; sin embargo, se pudo observar en algunos años un leve predominio de las hembras en el primer estrato altitudinal (Cuadro 5).

No obstante, en el año 2001 se reportó una composición atípica de la población, puesto que las hembras predominaron en el estrato superior (801 a $900 \mathrm{msnm}$ ) y en cinco más de los nueve estratos altitudinales evaluados. En el año 2004 se observó el dominio de las hembras en cinco de los nueve estratos. Desde el 2005 a la fecha, se reporta dominancia general de los ejemplares machos en casi todos los estratos evaluados.

Al respecto, se podría considerar que la variación del gradiente natural de distribución altitudinal de la especie se habría alterado al igual que en otras cuencas camaroneras probablemente debido a la mayor vulnerabilidad que presentan las hembras en la captura (no presentan una quela de mayor tamaño como mecanismo de defensa, como en los machos) y a la mayor accesibilidad para la pesca en los sectores medio e inferior de la cuenca donde comúnmente se distribuyen.

Los análisis anuales totales de la proporción sexual del camarón de río, mediante la prueba estadística no paramétrica del Chi cuadrado, muestran que la dominancia de los machos fue significativa en casi todos los años, con excepción del 2000 (proporción 1:1). 
Cuadro 6. Proporción sexual (Macho: Hembra) por años del camarón Cryphiops caementarius del río Cañete (2000-2015)

\begin{tabular}{ccc}
\hline Año & $\mathrm{M}: \mathrm{H}$ & $\mathrm{X}^{2}$ \\
\hline 2000 & $1: 0: 1.0$ & 0.1 \\
2001 & $0.8: 1.0$ & $10.5^{*}$ \\
2002 & $1.7: 1.0$ & $99.9^{*}$ \\
2004 & $0.7: 1.0$ & $18.8^{*}$ \\
2005 & $2.3: 1.0$ & $251.9^{*}$ \\
2006 & $1.7: 1.0$ & $126.4^{*}$ \\
2007 & $4.5: 1.0$ & $641.2^{*}$ \\
2008 & $2.0: 1.0$ & $145.3^{*}$ \\
2009 & $2.3: 1.0$ & $206.6^{*}$ \\
2010 & $2.7: 1.0$ & $226.3^{*}$ \\
2011 & $3.1: 1.0$ & $278.6^{*}$ \\
2012 & $2.3: 1.0$ & $147.9^{*}$ \\
2013 & $1.5: 1.0$ & $39.1^{*}$ \\
2014 & $3.3: 1.0$ & $370.3^{*}$ \\
2015 & $3.2: 1.0$ & $349.7^{*}$ \\
\hline
\end{tabular}

$*(p<0.0 .5)$

La dominancia de hembras fue significativa solo en 2001 y 2004 (Cuadro 6).

Estructura de la madurez gonadal

Las actividades de evaluación poblacional del camarón de río se realizaron mayormente entre los meses de julio y setiembre. Así, es de esperar que durante el pico de reproducción de los meses de verano, se observe una población compuesta por ejemplares de ambos sexos en estadio de maduración gonadal II (maduración incipiente).

La presencia de ejemplares hembras en estadios IV y V (desove y posdesove) en un bajo porcentaje evidencia la continuidad del proceso reproductivo a lo largo del año. Estos especímenes fueron colectados entre los 0 a $300 \mathrm{msnm}$, encontrándose en mayor nú- mero en las estaciones de muestreo próximas a la desembocadura del río.

El marco de maduración gonadal presentó ligeras variaciones en el periodo 20082010 , lo cual podría deberse, entre otros factores externos, a la construcción del puente del nuevo tramo de la Carretera Panamericana sobre el río Cañete, así como de la hidroeléctrica CELEPSA, que entró en operación en 2010. Aún se desconocen los efectos que tendrá a mediano y largo plazo la regulación del caudal en el sector medio de la cuenca por la operación de esta represa, así como el efecto barrera para la migración normal del camarón hacia las partes altas de la cuenca.

Los resultados anuales de la condición reproductiva reportan la predominancia de gónadas en estadio II (maduración incipiente), que en machos variaron entre $69.6 \%$ (2000) y $98.6 \%$ (2014) y en las hembras entre $55.2 \%$ (2004) y $94.4 \%$ (2014). Los porcentajes de estadios de madurez gonadal permiten observar un moderado retraso del proceso de maduración gonadal en 2007 y en menor grado en 2005. Asimismo, se aprecia un leve adelanto en el proceso de maduración en 2010, 2011 y 2012. Los demás resultados se ajustan a las características reproductivas del recurso para el periodo en que se ejecutaron las evaluaciones (Cuadros 7 y 8$)$.

\section{Aspectos Poblacionales de los Adultos}

Evolución anual de los índices de concentración

Los análisis de variación en la distribución de los índices de concentración evidencian la presencia de un moderado gradiente negativo de distribución altitudinal, tanto en la biomasa media como en la densidad del camarón de río. Esta condición coincide con lo reportado por diversos autores (Viacava et al., 1978; Wasiw y Yépez, 2015). 
Cuadro 7. Variación porcentual anual de los estadios de madurez gonadal (EMG) de machos del camarón Cryphiops caementarius en el río Cañete (2000-2015)

\begin{tabular}{cccccccccccccccc}
\hline EMG & 2000 & 2001 & 2002 & 2004 & 2005 & 2006 & 2007 & 2008 & 2009 & 2010 & 2011 & 2012 & 2013 & 2014 & 2015 \\
\hline I & 9.8 & 13.9 & 7.6 & 4.2 & 3.3 & 3.2 & 3.6 & 17.7 & 26.4 & 6.2 & 7.1 & 1.2 & 1.2 & 1.2 & 1.6 \\
II & 69.6 & 79.5 & 84.9 & 78.5 & 96.3 & 92.8 & 91.7 & 75.3 & 70.4 & 87.2 & 88.4 & 90.8 & 91.8 & 98.6 & 98.0 \\
III & 15.2 & 6.6 & 7.5 & 17.3 & 0.4 & 4.0 & 4.7 & 6.4 & 3.2 & 6.6 & 4.5 & 0.6 & 4.0 & 0.2 & 0.4 \\
IV & 5.4 & & & & & & & 0.6 & & & & 7.4 & 3.0 & & \\
\hline & 100 & 100 & 100 & 100 & 100 & 100 & 100 & 100 & 100 & 100 & 100 & 100 & 100 & 100 & 100 \\
\hline
\end{tabular}

Cuadro 8. Variación porcentual anual de los estadios de madurez gonadal (EMG) de hembras del camarón Cryphiops caementarius en el río Cañete (2000-2015)

\begin{tabular}{cccccccccccccccc}
\hline EMG & 2000 & 2001 & 2002 & 2004 & 2005 & 2006 & 2007 & 2008 & 2009 & 2010 & 2011 & 2012 & 2013 & 2014 & 2015 \\
\hline I & 3.1 & 8.9 & 3.8 & 4.2 & 6.4 & 4.1 & 6.0 & 8.9 & 13.9 & 7.2 & 13.0 & 0.3 & & & 1.0 \\
II & 83.8 & 79.5 & 85.7 & 55.2 & 90.0 & 89.0 & 94.0 & 81.2 & 80.4 & 83.5 & 77.8 & 91.3 & 90.5 & 94.4 & 93.6 \\
III & 8.4 & 8.8 & 3.1 & 33.1 & 3.6 & 2.3 & & 7.8 & 2.6 & 3.5 & 3.8 & 4.6 & 9.5 & 4.3 & 3.7 \\
IV & 4.7 & 2.8 & 7.4 & 7.5 & & 4.6 & & 2.1 & 3.1 & 3.3 & 4.6 & 3.8 & & 1.3 & 1.7 \\
V & & & & & & & & & & 2.5 & 0.8 & & & & \\
\hline & 100 & 100 & 100 & 100 & 100 & 100 & 100 & 100 & 100 & 100 & 100 & 100 & 100 & 100 & 100 \\
\hline
\end{tabular}

Los mayores valores de densidad y biomasa media de camarón durante el periodo de evaluación fueron registrados en el sector comprendido entre los 0 a $100 \mathrm{msnm}$. En 2004 se reportaron los menores índices de concentración del recurso. Asimismo, en 2005, 2006, 2008 y 2009 se registraron altos valores de la densidad y biomasa media en los estratos altitudinales medios (Figuras 6 y 7 ).

La disponibilidad del camarón de río está sujeta a diversos factores de carácter natural y antrópico. El grado de afectación de las poblaciones de camarón dependerá, entonces, de la interacción de este tipo de elementos que pueden en algún momento tener un fuerte impacto negativo sobre el recurso. Los factores que mayoritariamente influyen sobre la disponibilidad del recurso son los niveles del caudal hídrico y la intensidad de la actividad extractiva, tanto legal como ilegal. Así, en 2011, se presentó una ligera recuperación de los índices de concentración del recurso, los cuales decrecieron en 2012 y 2013. Si bien se reportó mayor densidad del recurso entre 2009 y 2011, esta densidad estaba representada por una población con biomasa media inferior a la registrada en 2005 y 2006. La densidad para todo el río varió entre 0.12 ind. $/ \mathrm{m}^{2}$ (2000) y 0.57 ind. $/ \mathrm{m}^{2}$ (2011) y la biomasa media, entre $0.84 \mathrm{~g} / \mathrm{m}^{2}$ (2000) y $4.57 \mathrm{~g} / \mathrm{m}^{2}$ (2006) (Figura 8).

\section{Distribución de biomasa y abundancia}

En líneas generales, en el periodo 20002015 las poblaciones evaluadas estuvieron compuestas en su mayoría por ejemplares con tallas inferiores a los $70 \mathrm{~mm}$, representando esta fracción el mayor aporte a la abundancia (Figura 9). En 2011 se presentó un incremento de la abundancia y biomasa absoluta de los ejemplares con tallas superiores a los $70 \mathrm{~mm}$ (42.9\%), registrándose el mayor va- 


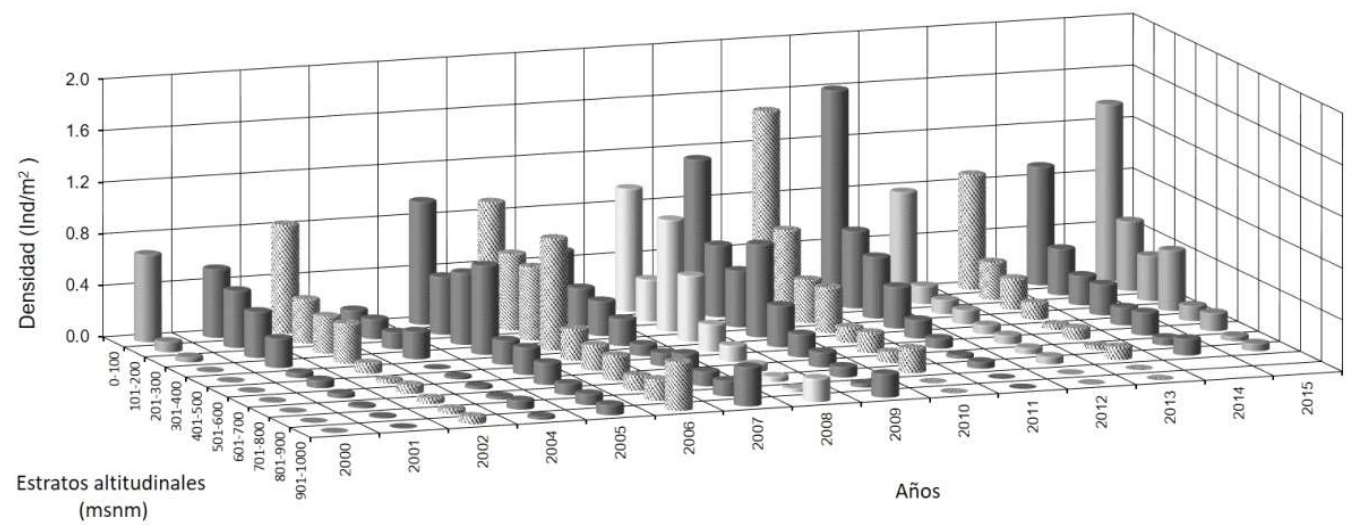

Figura 6. Variación anual de la densidad (ind $\left./ \mathrm{m}^{2}\right)$ por estratos altitudinales del camarón Cryphiops caementarius en el río Cañete (2000-2015)

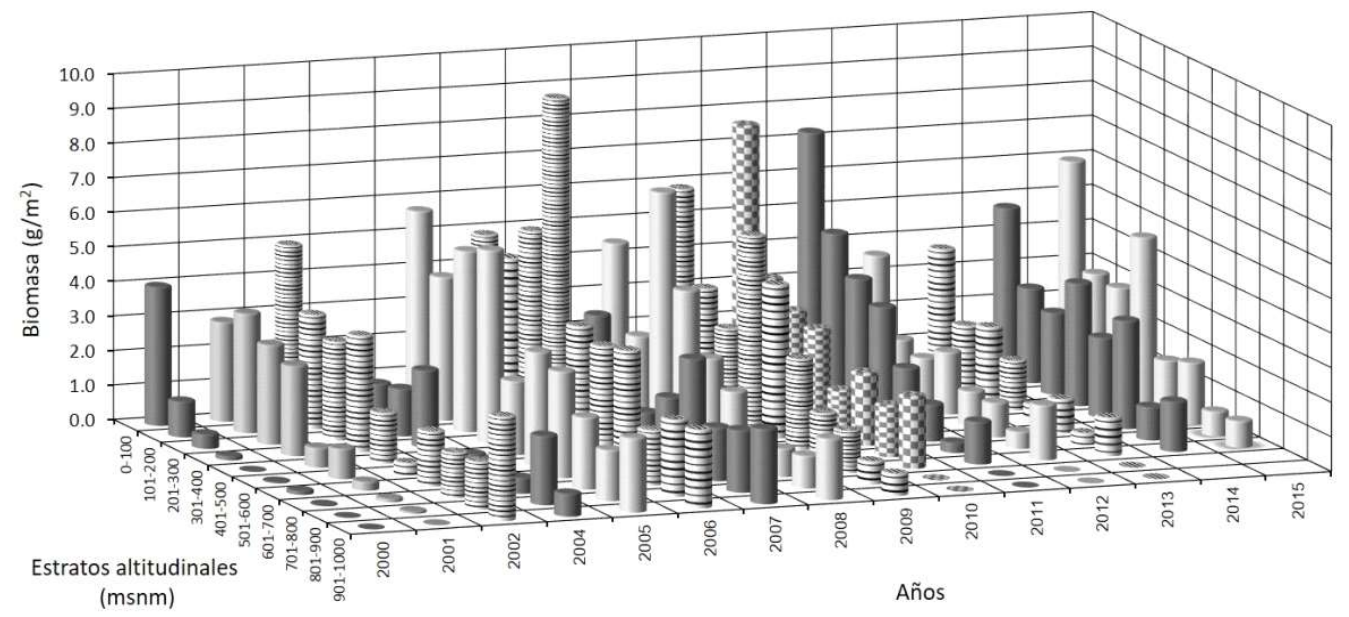

Figura 7. Variación anual de la biomasa $\left(\mathrm{g} / \mathrm{m}^{2}\right)$ por estratos altitudinales del camarón Cryphiops caementarius en el río Cañete (2000-2015)

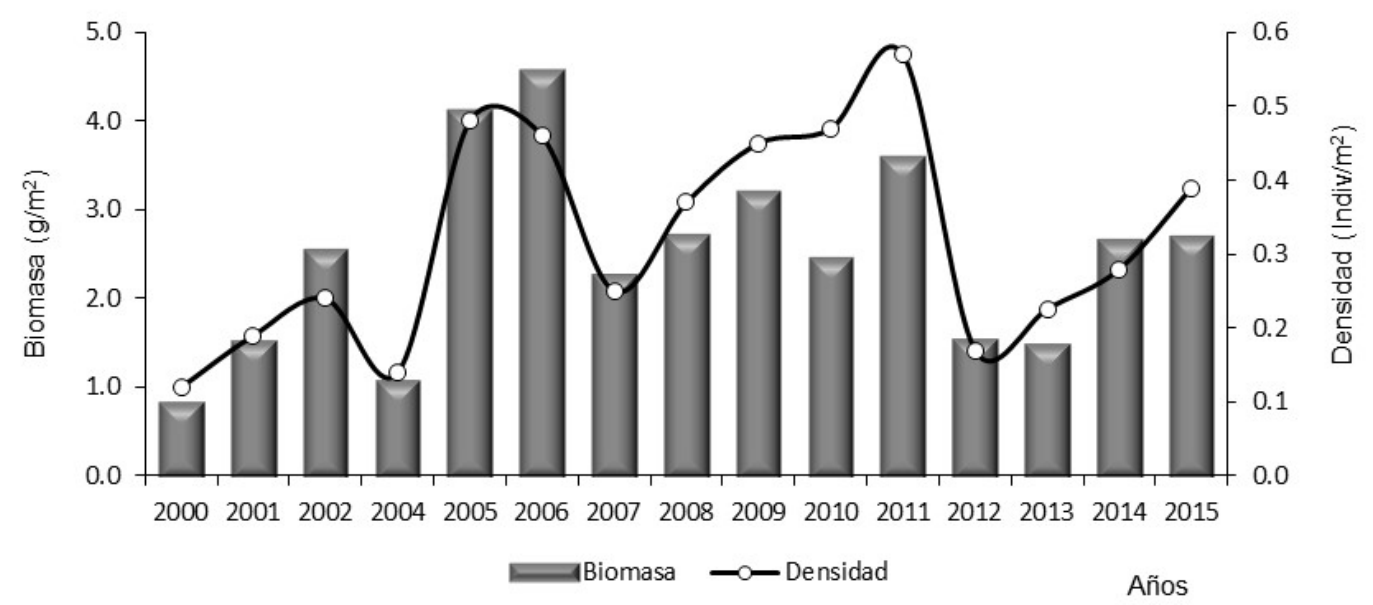

Figura 8. Variación anual de la biomasa y densidad del camarón Cryphiops caementarius en el río Cañete (2000-2015) 


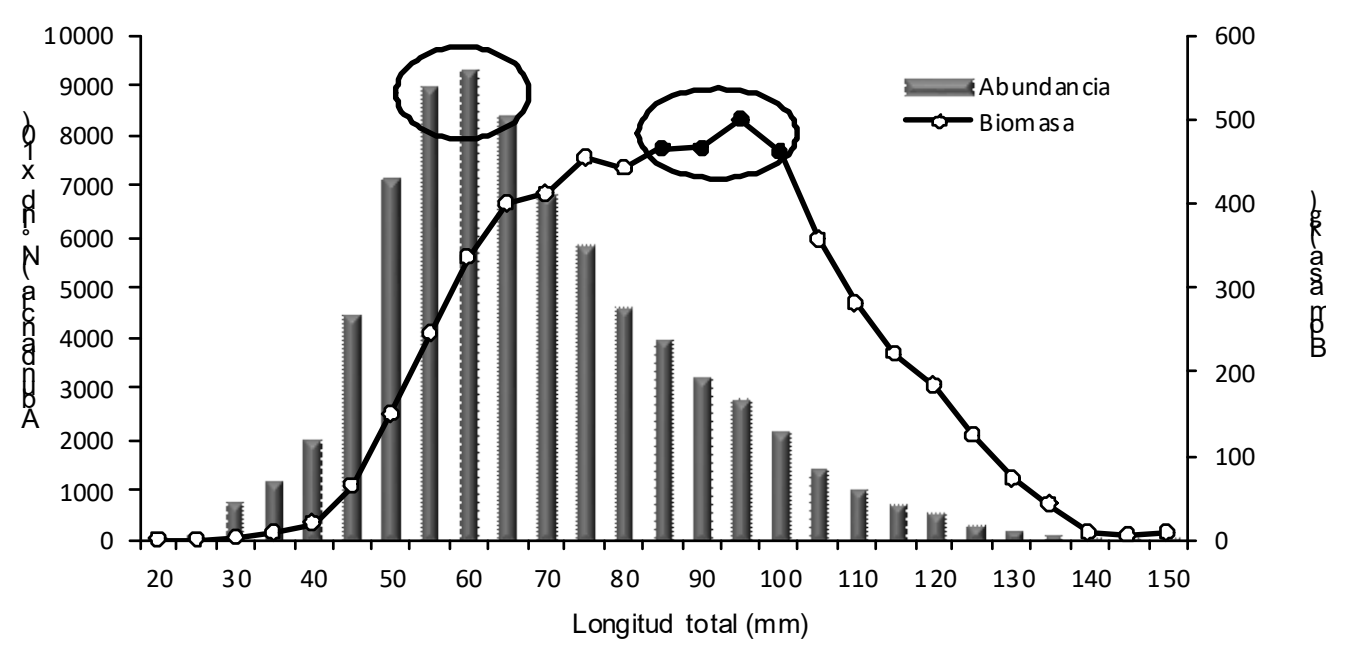

Figura 9. Abundancia y biomasa absoluta media del camarón Cryphiops caementarius, según tallas en el río Cañete (2000-2015)
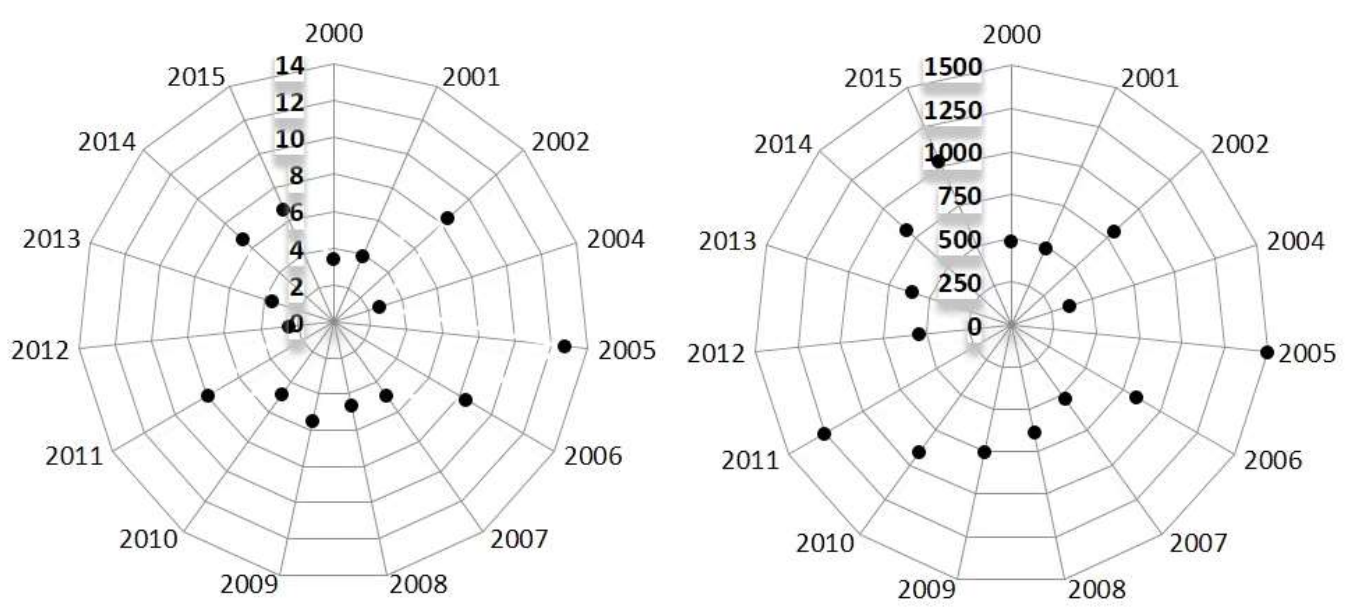

Figura 10. Biomasa absoluta anual (t) (lado izquierdo) y Abundancia anual $\left(\mathrm{N}^{\circ}\right.$ Individuos $\mathrm{x}$ 1000) (lado derecho) del camarón Cryphiops caementarius en el río Cañete (20002015)

lor de la biomasa absoluta por encima de esta talla; sin embargo, en 2014 la fracción de ejemplares mayores decrecieron moderadamente (41.9\%) y aún más en 2015 (25.8\%), posiblemente a consecuencia de los factores naturales y antrópicos anteriormente señalados.
El mayor aporte a la biomasa absoluta media, según tallas, correspondió a ejemplares entre 85 y $100 \mathrm{~mm}$ de longitud total. El análisis de los estimados de abundancia media determinó que los mayores aportes correspondieron a tallas entre 55 y $65 \mathrm{~mm}$ (Figura 9). 

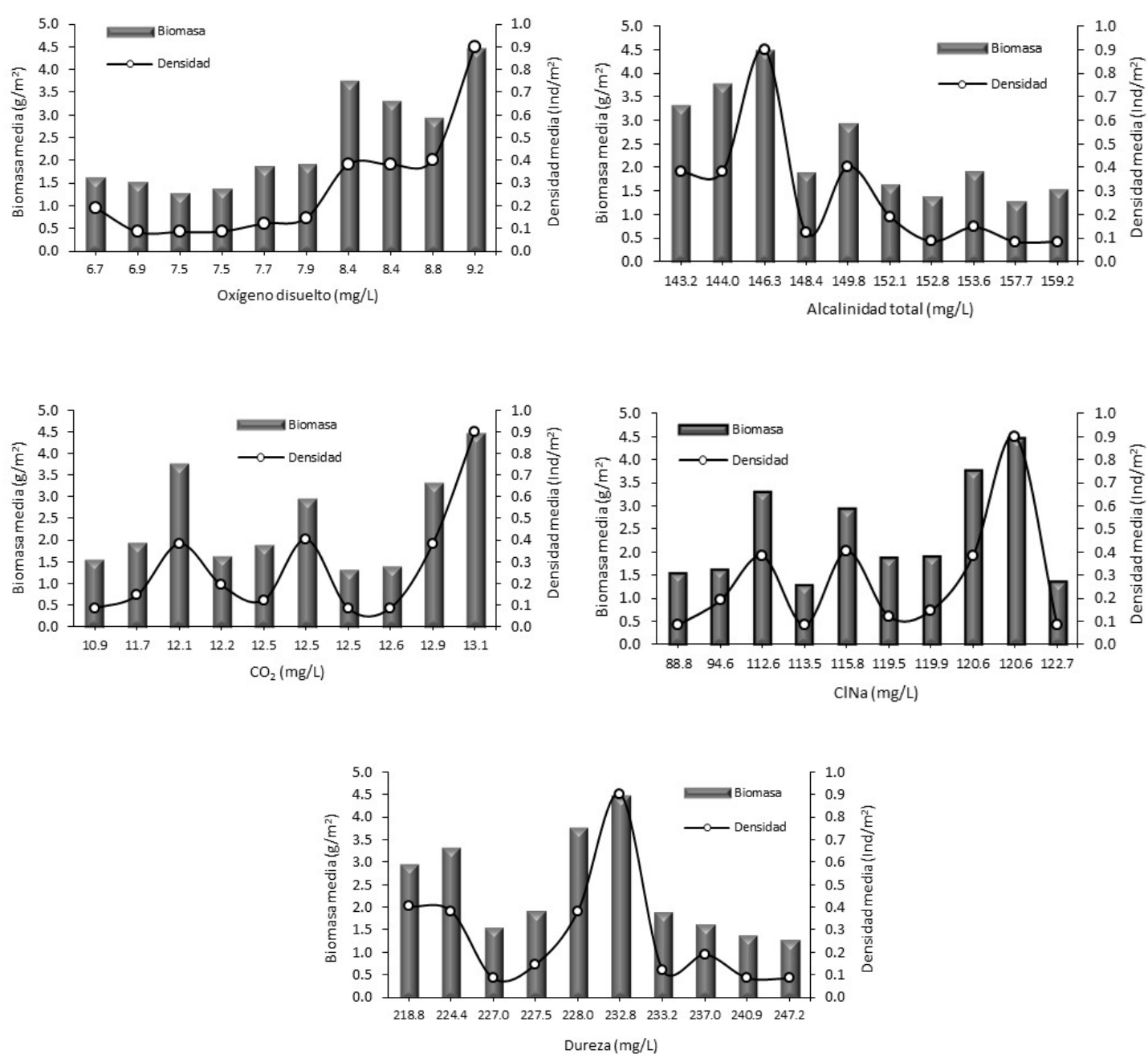

Figura 11. Correlación entre los parámetros físicoquímicos medios de calidad del agua con los índices poblacionales medios del camarón Cryphiops caementarius en el río Cañete (2000-2015)

A su vez, la abundancia y biomasa absoluta reportada en 2011 permitió inferir una ligera recuperación poblacional del recurso; sin embargo, en 2012 y 2013 se registraron fuertes decrementos de estos, llegando casi a una situación «crítica». A su vez, en 2014 y 2015 se registraron leves incrementos de la biomasa y abundancia (Figura 10).

Por otro lado, la tendencia evidenciada en la reducción de la densidad y biomasa media estaría asociada, entre otros factores a los ya señalados, a la pesca intensa en la zona de estuario y al incumplimiento del periodo veda por reproducción, así como a las alteraciones en el cauce del río, producto de las obras que se ejecutan sobre el cauce desde hace más de una década. Actualmente, el efecto combinado de todos estos factores estaría conduciendo al declive de la población de camarón en el río Cañete, siendo pertinente que las autoridades del Sector adopten las medidas correctivas necesarias para la protección y recuperación poblacional del recurso 


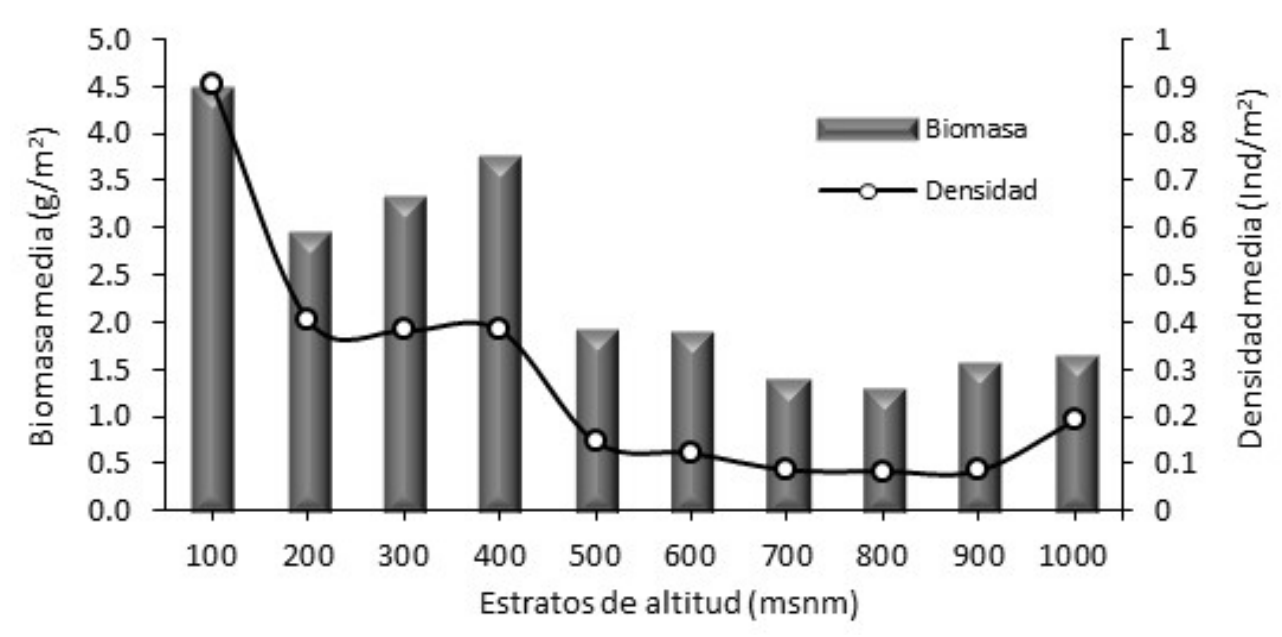

Figura 12. Correlación entre los estratos de altitud (msnm) con los índices poblacionales medios del camarón Cryphiops caementarius en el río Cañete (2000-2015)

(concienciación de pescadores y pobladores sobre pesca responsable y el acatamiento a las medidas normativas de protección).

\section{Relación Recurso Ambiente}

Los valores de los parámetros fisicoquímicos evidencian variaciones que podrían haber sido originadas por alteraciones de las condiciones climatológicas, cambios estacionales, contaminación de origen antrópico y modificaciones en el curso de los ríos; no obstante, no se descarta la posibilidad que estas alteraciones puedan relacionarse con la presencia de contaminantes (pesticidas, insecticidas y otros) empleados en actividades agrícolas y en la pesca ilegal del recurso.

A fin de medir la relación lineal entre dos variables cuantitativas, se empleó el coeficiente de correlación de Pearson $(\rho x, y)$. Para el caso, se contrastaron los valores medios de algunos parámetros de calidad del agua (como oxígeno disuelto, alcalinidad total, dureza, cloruros y $\mathrm{CO}_{2}$ libre) y de los estratos de altitud, con los índices de biomasa media del recurso (Figuras 11 y 12) (es muy similar la relación de estos parámetros con la densidad relativa), observándose lo siguiente: Oxígeno medio disuelto $\mathrm{O}_{2}(\mathrm{mg} / \mathrm{L})$

Se observó una correlación positiva alta (valor de «ri con respecto a la biomasa media fue 0.87 ). Se observa que entre los valores de 6.7 a $7.9 \mathrm{mg} / 1$ de oxígeno disuelto, el incremento de los índices de concentración de camarón es moderado; sin embargo, estos se incrementan significativamente a medida que aumenta la concentración del oxígeno disuelto. Según ello, al camarón le favorecería más las aguas con buena oxigenación; en este caso, con concentraciones mayores de $8.0 \mathrm{mg} / \mathrm{L}$ (Figura 11).

\section{Alcalinidad total media $(\mathrm{mg} / \mathrm{L})$}

Se presentó una correlación negativa alta (valor de «rr» con respecto a la biomasa media fue -0.82). Valores superiores de 150 $\mathrm{mg} / \mathrm{L}$ de alcalinidad total influirían negativamente sobre los índices poblacionales del camarón; apreciándose que los valores registrados tipifican a la alcalinidad del agua del río en un rango de medio a levemente alto (Figura 11). 


\section{Dureza total media $(\mathrm{mg} / \mathrm{L})$}

Evidenció correlación negativa baja, donde el valor de $\langle\mathrm{r}\rangle$ con respecto a la biomasa media fue -0.35 . Se observó además que los valores registrados (224.2 y 250.8 $\mathrm{mg} / \mathrm{l}$ de dureza total) no influirían negativamente sobre los índices poblacionales del camarón en el río Cañete. Asimismo, se determinó que el agua del río corresponde al tipo de agua dura (200-400 mg/L) (Figura 11). Es pertinente indicar que se ha reportado la presencia del camarón en aguas de tipo muy duras $(>400 \mathrm{mg} / \mathrm{L})$ como es el caso del río Sama (Tacna) (Wasiw y Yépez, 2015).

\section{Cloruro de sodio ClNa $(\mathrm{mg} / \mathrm{L})$}

Se presentó correlación positiva moderada con los índices de biomasa media $(\mathrm{r}=0.48)$. Esto implica que el cloruro de sodio tendría influencia leve sobre los índices de concentración del camarón en el río Cañete. Se infiere que valores superiores a $123 \mathrm{mg} / 1$ de $\mathrm{ClNa}$ podrían afectar los índices poblacionales del recurso (Figura 11).

\section{Anhídrido carbónico libre $\mathrm{CO}_{2}(\mathrm{mg} / \mathrm{L})$}

Presentó correlación positiva alta con los índices de biomasa media $(\mathrm{r}=0.36)$. De acuerdo a lo observado, se puede inferir que el $\mathrm{CO}_{2}$ libre influye favorablemente sobre los índices de concentración del camarón en el río Cañete; sin embargo, valores superiores a $13.1 \mathrm{mg} / 1$ de $\mathrm{CO}_{2}$ podrían afectar los índices poblacionales del recurso, considerando que se trata de un gas tóxico proveniente de la descomposición bacteriana y respiración de los organismos del cuerpo de agua (Figura 11).

\section{Estratos de altitud (msnm)}

Presentó una correlación negativa alta con los índices de biomasa y densidad de camarón, lo que implica que los índices de concentración del recurso presentan un gradiente inverso de distribucional altitudinal por estratos (el valor de « rr» con respecto a la biomasa media fue -0.86) (Figura 12). Este resultado concuerda con lo señalado por otros investigadores (Viacava et al., 1978).

\section{Conclusiones}

- Se observó una ligera tendencia a la reducción de las tallas máximas del camarón Cryphiops caementarius en el río Cañete.

- Se evidenciaron alteraciones en los parámetros fisicoquímicos evaluados; sin embargo, en líneas generales, las aguas del río Cañete presentaron características aceptables para el desarrollo de los estadios vitales del recurso camarón.

- Los valores anuales de la relación longitud - peso evidenciaron que el camarón presenta mayor peso con respecto a su correspondiente talla (coeficiente de crecimiento $b>3.0$ ). Las variaciones anuales de «b» no fueron estadísticamente significativas, y fluctuaron entre 3.13 (2004) y 3.35 (2010), que corresponde a un crecimiento de tipo isométrico.

- Las variaciones anuales de los índices de concentración del camarón evidencian cambios significativos que estarían ligados principalmente a factores naturales y antrópicos. Se observaron valores críticos en el 2004 y 2012, con cierta recuperación del recurso en los últimos años.

\section{Literatura Citada}

1. Amaya de G, Guerra A. 1976. Especies de camarones de los ríos norteños del Perú y su distribución. Informe del Convenio Ministerio de Pesquería Univ Trujillo. Ministerio de Pesquería, Lima, Perú. 58 p.

2. Báez P. 1985. Fenómeno El Niño, elemento importante en la evolución del camarón de río (Cryphiops caementarius). Inv Pesq Chile 32: 235-242. 
3. Bahamonde N, Vila I. 1971. Sinopsis sobre la biología del camarón de río del norte. Biol Pesq 5: 3-60.

4. Carlander K. 1969. Handbook of freshwater fishery biology. Vol 1. USA: Iowa State University Press. $752 \mathrm{p}$.

5. Castro C. 1966. El camarón de río del norte Cryphiops caementarius (Molina). Est Oceanol Chile 2: 11-19.

6. Chávez $R$, De Parodi E, Villegas J. 1973. Estudio del Cryphiops caementarius (Molina) (camarón de río). Rev Invest Univ Nac San Agustín 2(1): 13-34.

7. Espino M, Wosnitza-Mendo C. 1984. Manuales de evaluación de peces $\mathrm{N}^{\circ} 1$, Área barrida. Inf Inst Mar del Perú N. ${ }^{\circ}$ $86.31 \mathrm{p}$.

8. Guevara M. 2003. Morfología fluvial. Curso de obras de control fluvial. Universidad del Cauca.

9. Hartmann G 1958. Apuntes sobre la biología del camarón de río, Cryphiops caementarius (Molina) Palaemonida, Decapada. Pesca y Caza (Lima) 8: 15-28.

10. Meruane J, Rivera M, Morales $C$, Galleguillos C, Hosokawa, H. 2006. Juvenile production of the freshwater prawn Cryphiops caementarius (Decapoda: Palaemonidae) under laboratory conditions in Coquimbo, Chile. Gayana 70: 228-236.
11. Norambuena R. 1997. Antecedentes biológicos de Cryphiops caementarius (Molina, 1782) en el estero «El Culebrín» (crustacea, Decapada, Palaemonidae). Biol Pesq 9: 7-19.

12. Rivera M, Schmiede P, Meruane J. 1983. Desarrollo larval del camarón de río del norte Cryphiops caementarius (Molina, 1782) (Crustacea: Palaemonidae), en condiciones de laboratorio. En: Simposio Internacional de Acuacultura. Coquimbo, Chile.

13. Viacava M, Aitken R, Llanos J. 1978. Estudio del camarón en el Perú 19751976. Bol IMARPE 3(5): 165-232.

14. Wasiw J, Yépez V. 2015. Evaluación poblacional del camarón Cryphiops caementarius en ríos de la costa sur del Perú. Informe Anual Interno 2015. AFIRAC-IMARPE.

15. Wasiw J, Yépez V. 2015. Evaluación poblacional del camarón Cryphiops caementarius en ríos de la costa sur del Perú. Rev Inv Vet Perú 26: 166-181. doi: 0.15381/rivep.v26i2.11103

16. Yépez V. 2009. Consideraciones acerca de la distribución y extracción del recurso «camarón» en ríos de la costa peruana. Revista Pesca (julio-agosto). p 9-11. 